\title{
ROMP COMO UM MÉTODO VERSÁTIL PARA A OBTENÇÃO DE MATERIAIS POLIMÉRICOS DIFERENCIADOS
}

Valdemiro P. Carvalho Jr., Camila P. Ferraz, José Luiz S. Sá e Benedito S. Lima-Neto*

Instituto de Química de São Carlos, Universidade de São Paulo, CP 780, 13560-970 São Carlos - SP, Brasil

Recebido em 28/6/11; aceito em 27/10/11; publicado na web em 4/1/12

ROMP AS A VERSATILE METHOD FOR THE OBTENTION OF DIFFERENTIATED POLYMERIC MATERIALS. Ring Opening Metathesis Polymerization (ROMP) of cyclic olefins is a powerful transition metal-catalyzed reaction for syntheses of polymers and copolymers. The key feature of this reaction is the [2+2]-cycloaddition mechanism, with retention of the olefinic unsaturation in the polymer chain and occurrence of living polymerization. With the development of metal-carbene type catalysts for this process, many addressed polymeric materials have been successfully prepared to be employed in several fields of the science and technology. This review summarizes recent examples of syntheses of polymers with amphiphilic features such as block, graft, brush or star copolymers; as well syntheses of biomaterials, dendronized architectures, photoactive polymers, cross-linked or self-healing materials, and polymers from renewed supplies.

Keywords: ROMP; olefin metathesis; polymer.

\section{INTRODUÇÃo}

ROMP (ring opening metathesis polymerization) é um tipo de reação de metátese de olefinas cíclicas que reagem por abertura do anel ao ocorrer o intercruzamento dos carbonos olefínicos, resultando em um polímero com retenção da insaturação (Esquema 1). ${ }^{1,2}$

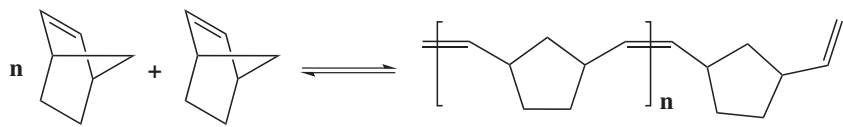

Esquema 1. ROMP de NBE para formação de poliNBE

A reação de ROMP está atualmente reconhecida e é muito empregada em química de polímeros. ${ }^{3}$ Sua diversidade de aplicação e vantagens frente às clássicas polimerizações vinílicas fizeram com que muitos pesquisadores começassem a utilizar essa metodologia para a obtenção de novos materiais poliméricos. Muitas metodologias de polimerização já foram readequadas para ROMP, por se tratar de procedimento que considera os princípios da Química Verde, ${ }^{4}$ apresentando ganhos em relação a metodologias bem estabelecidas que envolvam muitas etapas e que usam reagentes nocivos.

Trata-se de uma reação relativamente nova quanto ao seu desenvolvimento, porque só teve um avanço significativo há cerca de 20 anos em virtude do aprimoramento de catalisadores para viabilizá-la, embora metátese de olefinas seja conhecida e aplicada industrialmente desde meados do século XX. ${ }^{1,2,5}$

O planejamento e desenvolvimento desses catalisadores só se deram graças à elucidação do mecanismo da reação, em 1971, por Yves Chauvin (Institut Français du Pétrole), onde ficou demonstrado que espécies carbenos coordenadas a um metal de transição são essenciais à catálise do processo. ${ }^{6}$ Desde então, muitos catalisadores foram sintetizados até que nos anos 90, Robert H. Grubbs (CALTECH) e Richard R. Schrock (MIT) obtiveram catalisadores de rutênio, molibdênio e tungstênio que se destacaram em uma diversidade de aplicações (Figura 1)..$^{7-11}$

Para entender melhor as características da reação de ROMP,

*e-mail: benedito@iqsc.usp.br

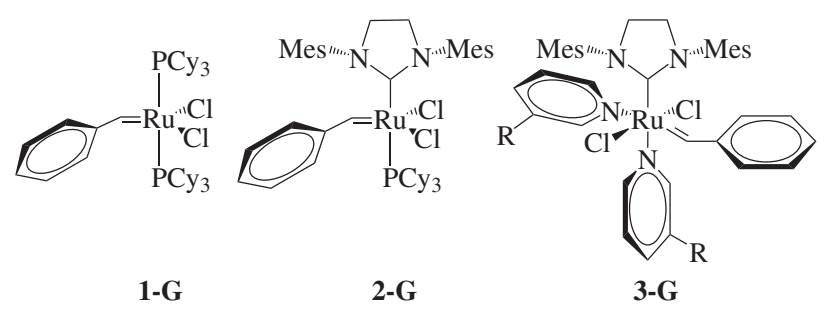

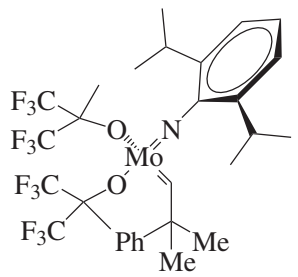

$\mathbf{S}$

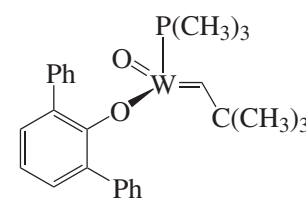

$\mathbf{S}$
Figura 1. Catalisadores de primeira (1-G), segunda (2-G) e terceira (3-G) geração de Grubbs e catalisadores de Schrock (S)

deve-se observar o mecanismo de reação (Esquema 2). ${ }^{1,2,7}$ A reação se inicia pela coordenação da olefina ao complexo metalocarbeno para que ocorra uma cicloadição [2+2] com a formação do intermediário metalociclobutano. Em seguida, ocorre o rearranjo das ligações metal-carbono para formar uma nova espécie metalocarbeno, que é a primeira unidade polimérica (etapa de iniciação; $k_{\mathrm{i}}$ ). As mesmas etapas voltam a ocorrer na presença de mais monômeros, formando a cadeia polimérica (etapa de propagação; $k_{\mathrm{p}}$ ). É importante observar que o processo continua até que todo o monômero seja consumido, devido à presença contínua da unidade metalocarbeno em uma das extremidades do polímero. Essa característica de reação do tipo viva é importante, porque se pode controlar o tamanho da cadeia, a formação de copolímeros ou o grau de entrecruzamento. Como já comentado, uma característica marcante nesse tipo de reação é a retenção da insaturação ao longo da cadeia do polímero, ao contrário da polimerização vinílica.

A reação de ROMP, considerando-se as velocidades de iniciação $\left(k_{\mathrm{i}}\right)$ e propagação $\left(k_{\mathrm{p}}\right)$, depende da natureza do metal e dos ligantes 


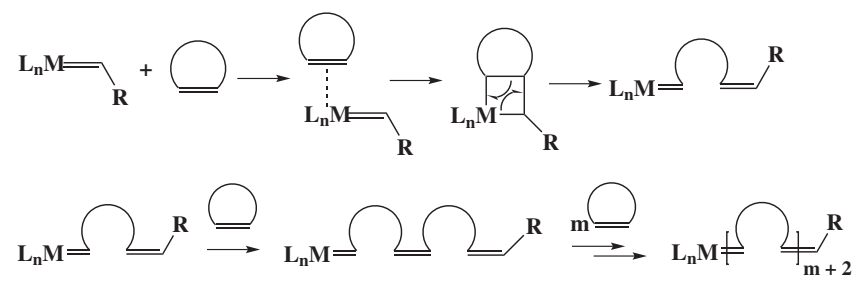

Esquema 2. Mecanismo de reação de ROMP

coordenados a ele, da unidade carbeno inicial e daquela que se propaga, bem como do substrato. Consequentemente, as condições de síntese dos polímeros, bem como suas microestruturas e propriedades físico-químicas, estão intimamente vinculadas às características do catalisador. Os que mais se destacam são os catalisadores do tipo Grubbs, em que os centros de rutênio têm maior seletividade por olefinas e são menos sensíveis à umidade e solventes próticos. ${ }^{2,7}$

Com o sucesso da disponibilidade de catalisadores, a metátese de olefinas tem proporcionado avanços em diversas áreas da ciência e tecnologia, tais como as de materiais poliméricos, médicas e biológicas. ${ }^{3}$ Por propiciarem esse desenvolvimento, os pesquisadores Chauvin, Grubbs e Schrock foram laureados com Prêmio Nobel de Química em 2005.

Essa revisão tem por objetivo apresentar exemplos das investigações científicas em síntese de materiais anfifílicos do tipo copolímeros em bloco, aleatórios, enxertados, em escova e estrela, biocompatíveis, polímeros dendronizados, polímeros fotoativos, polímeros reticulados, sistemas poliméricos para autocura e polímeros obtidos a partir de fontes renováveis. Não se trata de um trabalho exaustivo, mas que sejam observadas as circunstâncias e o potencial aplicativo da reação de ROMP.

\section{POLÍMEROS ANFIFÍLICOS}

Polímeros com partes hidrofílicas e partes hidrofóbicas são constituídos por diferentes grupos funcionais que podem se automontar em estruturas supramoleculares mediante condições seletivas. Podem formar micelas, estabilizantes em emulsões ou dispersões, cristais líquidos ou materiais semicristalinos e agentes transportadores de drogas. ${ }^{12,13}$ Geralmente, são copolímeros em bloco, aleatórios, enxertados, em escova ou estrela.

Por um lado, o conhecimento das conformações desses polímeros em diferentes condições, como o valor de $\mathrm{pH}$ e a temperatura que induzem à transição enovelada a globular, bem como o controle da morfologia de materiais poliméricos, é de fundamental importância para suas aplicações. ${ }^{12,13}$ Por outro, para que se tenha sucesso na obtenção de tais polímeros, as sínteses requerem planejamentos pertinentes para unir as diferentes partes que o constituirão. A reação via ROMP tem proporcionado que isso seja alcançado por ser um processo de fácil inserção molecular. A seguir, são apresentados alguns exemplos desses procedimentos.

\section{Funcionalização de grupos terminais}

A funcionalização de grupos terminais em cadeias poliméricas permite a síntese de polímeros monotelequélicos ou telequélicos. Com esses grupos, os polímeros obtidos via ROMP podem ser facilmente ligados a outros, expandindo-os para estruturas mais complexas, tais como copolímeros estrela, enxertados e multiblocos. Em geral, podem-se selecionar na literatura três diferentes estratégias para a obtenção de polímeros funcionais terminais via ROMP. ${ }^{14}$

Uma primeira abordagem é realizar a reação de ROMP com um carbeno-complexo onde a unidade carbeno já é o grupo de interesse. Por exemplo, a troca do benzilideno nos catalisadores de Grubbs por um alquilideno com a funcionalidade desejada, tornando-o diretamente a extremidade da cadeia polimérica. ${ }^{15}$ Porém, esta estratégia exige a síntese de um catalisador correspondente para cada novo grupo funcional terminal desejado (Esquema 3a).

Uma metodologia mais simples é o uso de um AT (agente de terminação), o qual deve conter grupos olefínicos ou vinílicos. Os AT mais comumente usados são éteres vinílicos que podem terminar a reação ou, quando substituídos, podem inserir grupos funcionais especiais (Esquema 3b). ${ }^{16}$

$\mathrm{Na}$ terceira abordagem, duas rotas são utilizadas: uso de ATC (agente de transferência de cadeia) durante a polimerização ou síntese de sacrifício. ATC é, geralmente, uma olefina acíclica interna que sofre uma reação de metátese cruzada com o carbeno da cadeia polimérica em crescimento. Essa estratégia permite a síntese de polímeros mono ou telequélicos, dependendo da sequência em que monômero e o ATC são adicionados (Esquema 3c). ${ }^{17-19} \mathrm{Na}$ síntese de sacrifício, um copolímero em bloco é formado. Um dos blocos é, então, clivado da cadeia polimérica, o qual é destruído em uma reação de desproteção onde o grupo funcional desejado é liberado (Esquema 3d). ${ }^{20}$

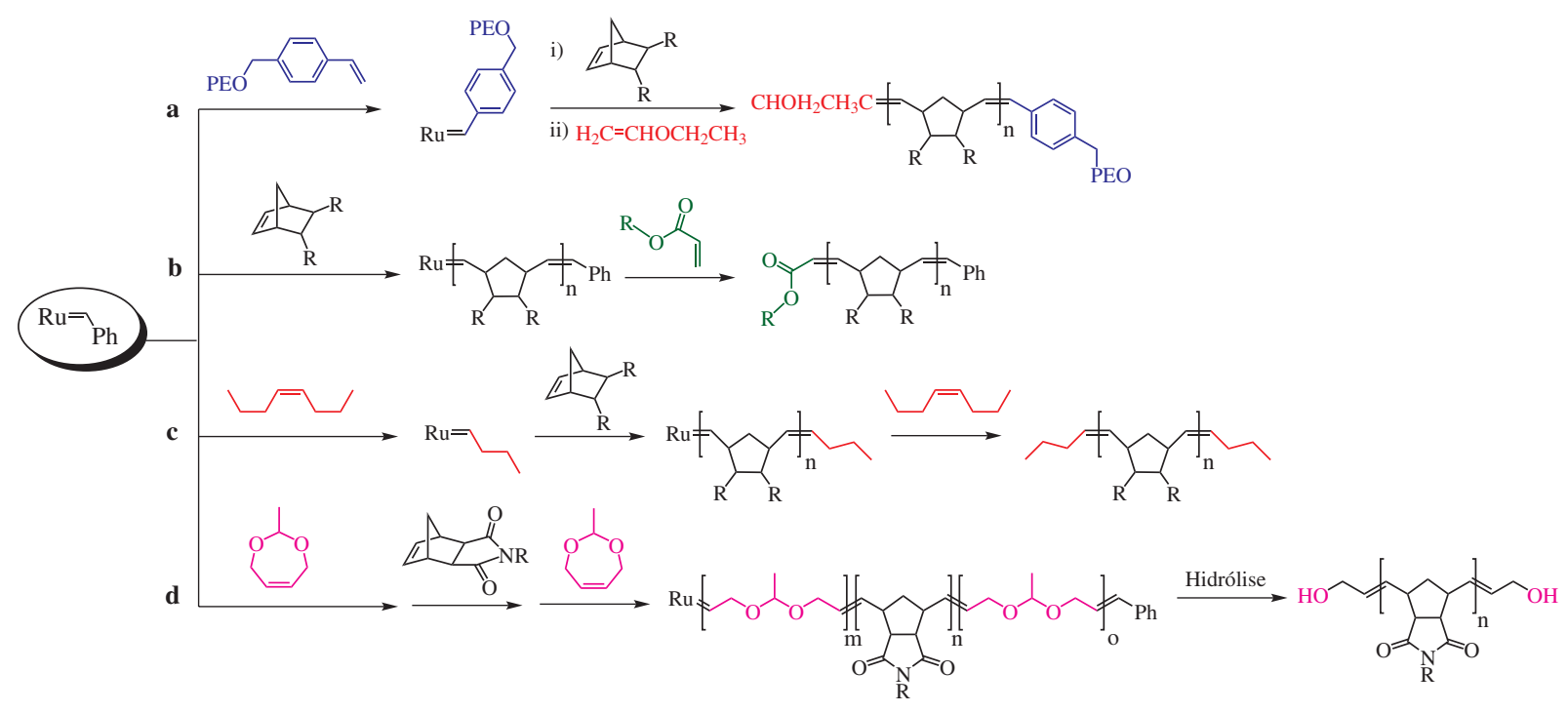

Esquema 3. Estratégias para a funcionalização de grupos terminais em polímeros 


\section{Polímeros em bloco e aleatórios}

A automontagem de copolímeros em bloco propicia a formação de materiais nanoestruturados para aplicações em eletrônica, optoeletrônica, biotecnologia, ${ }^{21-23}$ tintas, ${ }^{24} \operatorname{cosméticos},{ }^{25}$ materiais elétricos e eletro-ópticos, ${ }^{26}$ biossensores,${ }^{27}$ terapia gênica, ${ }^{21}$ etc.

Os fatores que regem as transformações morfológicas de copolímeros em blocos incluem a polaridade, a fração de volume e o tamanho relativo de cada bloco, a flexibilidade da cadeia, a temperatura do meio, a concentração inicial de polímero, a composição de mistura de solventes e aditivos, etc. ${ }^{23}$

Síntese de copolímeros anfifílicos em bloco via ROMP têm permitido um bom controle do tamanho dos blocos. ${ }^{28}$ Por exemplo, uma série de copolímeros com diferentes comprimentos de cadeia e comprimentos de bloco foi preparada com grupos de ácido carboxílico na parte hidrofílica e grupos dimetilésteres na parte hidrofóbica. ${ }^{29} \mathrm{~A}$ automontagem desses polímeros ocorreu em etanol como um solvente seletivo, observando-se boas correlações de tamanho e de dimensões da estrutura caroço-casca das micelas com as constituições dos blocos. Outros estudos mostraram a separação de microfases dos polímeros no estado sólido e os comportamentos das micelas com mudanças no valor de $\mathrm{pH}$ e da força iônica do meio. ${ }^{30}$

A separação de fases de copolímeros dibloco pode formar nanodomínios de blocos hidrofílicos para incorporação de sais metálicos. ${ }^{31}$ Por exemplo, poli[NBE- $b$-(NBE-diácido carboxílico)] foram preparados com proporções diferentes de bloco para formar micelas que foram utilizadas para incorporar íons de ferro e produzir nanopartículas de óxido de ferro. ${ }^{32}$

ROMP é um dos métodos para preparar copolímeros do tipo rodcoil. ${ }^{33} \mathrm{O}$ poli[(3-alquiltiofeno)- $b$-lactida] (P[3AT- $b$-LA] $)$ regiorregular foi sintetizado a partir do P3AT términofuncionalizado, o qual foi usado como macroiniciador para a ROMP controlada da D,L-lactida. ${ }^{34}$

Síntese de polímeros multiblocos a partir de diversos NBEs funcionalizados também foram muito exploradas via ROMP na obtenção de polímeros contendo açúcares e carboidratos. ${ }^{35}$ Copolímeros cliváveis pentabloco tipo ABABA e heptabloco tipo ABABABA também foram obtidos por síntese de sacrifício via ROMP de acetais cíclicos de sete membros e de derivados de NBE com dicarboximida $\mathrm{N}$-substituídos. ${ }^{20}$ Embora esses métodos sejam robustos para sintetizar diferentes tipos de copolímeros multiblocos, ${ }^{36}$ é de interesse a busca por outras estratégias sintéticas em condições brandas.

Processos por polimerização aniônica, NMP (polimerização mediada por nitróxido), RAFT (transferência de cadeia reversível por adição-fragmentação) e ATRP (polimerização radicalar por transferência de átomo) são eficazes para a polimerização de uma gama limitada de monômeros, o que reduz a diversidade de obtenção de copolímeros anfifílicos em bloco. ${ }^{15,37,38}$ Para contornar essa limitação, a combinação dessas técnicas com a ROMP tem demonstrado ser uma metodologia alternativa para a obtenção de novos materiais. Macroiniciadores duplos para reações de ROMP e ATRP puderam iniciar os diferentes tipos de polimerizações de forma independente e seletiva. ${ }^{15,38}$

Outros exemplos utilizando ROMP-polimerização aniônica já foram relatados na literatura como um método viável e fácil para a síntese de copolímeros dibloco. ${ }^{39} \mathrm{Um}$ exemplo foi a obtenção de poli[(ácido lático)- $b$-NBE] por combinação da ROMP de NBE com ROP (polimerização por abertura de anel) do lactídeo. ${ }^{40}$

A síntese de um copolímero tribloco $\mathrm{ABA}$ em líquido iônico [bmim] $\left[\mathrm{BF}_{4}\right]$, onde bmim é o íon 1-butil-3-metilimidazolium, foi realizada a partir de um macroiniciador telequélico derivado de NBE contendo um bromo terminal compatível com o líquido iônico e com o ATC. ${ }^{37}$ A reação apresentou um bom controle sobre o processo de polimerização resultando em IPD (índice de polidispersidade) com baixo valor (1,25-1,55). O copolímero espontaneamente se automontou em água para formar micelas (Esquema 4).

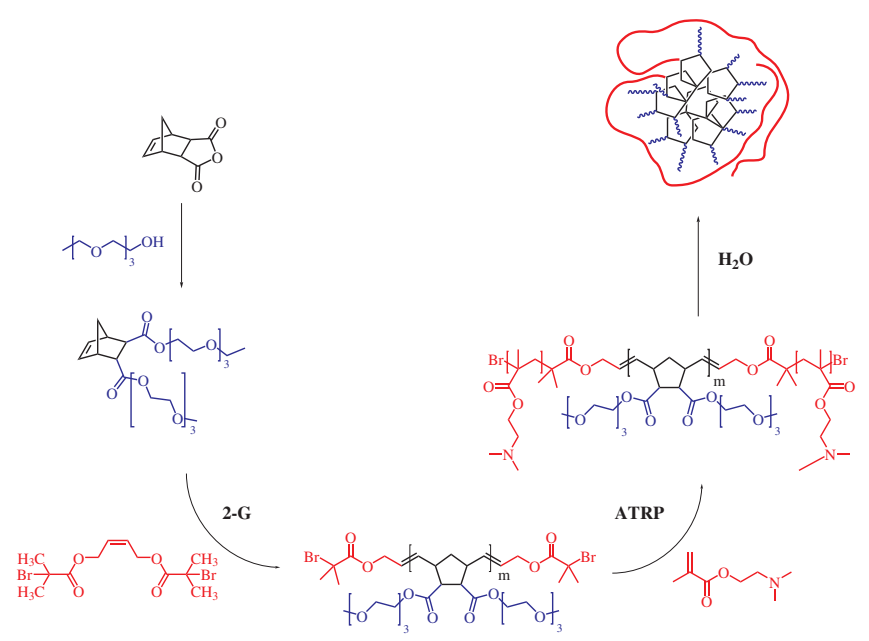

Esquema 4. Síntese de copolímero tribloco ABA via ROMP-ATRP e a formação da micela em água. Adaptado da ref. 37, com permissão da Elsevier

Copolímeros triblocos ABA foram sintetizados por combinação entre RAFT e ROMP a partir de monômeros mecanisticamente incompatíveis, tais como 1,5-ciclo-octadieno com estireno e acrilato. ${ }^{19}$

Foi investigada também a síntese via RAFT de polímeros funcionalizados com NBE para, então, ocorrer reações de ROMP. ${ }^{41}$ Por exemplo, um copolímero tribloco ABA de estireno e estireno funcionalizado com NBE foi preparado por polimerização via RAFT seletiva (Esquema 5). Posteriormente, os grupos norbornenil foram polimerizados via ROMP formando um polímero estrela. ${ }^{42}$

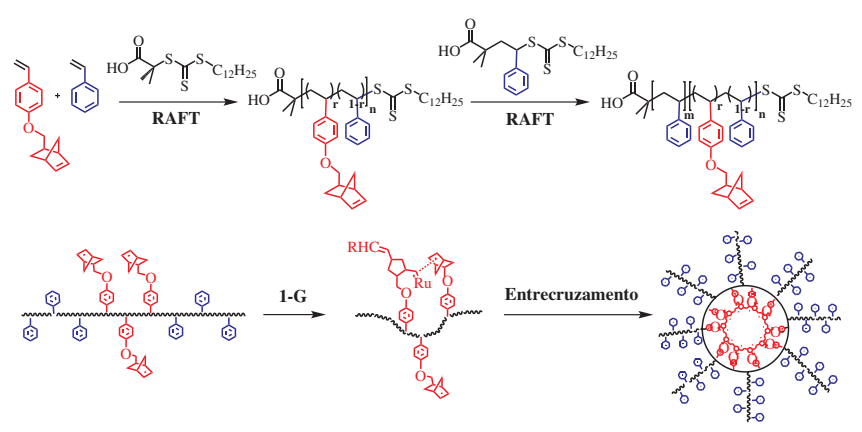

Esquema 5. Síntese de copolímero tribloco via RAFT seguido pela polimerização do norbornenil via ROMP para formação do polímero estrela. Adaptado da ref. 42, com permissão da CSIRO Publishing

Química click tem sido utilizada em química de polímeros devido à alta eficiência, confiabilidade, reações com condições simples e alto rendimento. ${ }^{43}$ Dessa forma, teve-se o interesse na síntese de copolímeros em bloco de polioxaNBE funcionalizado por uma combinação de ROMP e reação click ${ }^{44}$ Essa combinação foi também utilizada na preparação de copolímeros multiblocos. Polibutadieno telequélico difuncionalizado com bromo foi sintetizado pela ROMP de 1,5-ciclobutadieno na presença de um ATC difuncional simétrico. ${ }^{36}$ Esse polímero foi transformado em um polibutadieno telequélico diazo, que, após a reação $c l i c k$, formou polibutadienos multiblocos contendo o cromóforo azobenzeno e grupos triazol.

\section{Polímeros enxertados}

Copolímeros enxertados oferecem a possibilidade única de 
agregar propriedades dos materiais através de inúmeras variáveis estruturais que podem ser modificadas, como a natureza da cadeia principal do polímero e a composição e densidade dos enxertos. ${ }^{45}$ Esses polímeros têm sido desenvolvidos de muitas maneiras a fim de gerar estruturas supramoleculares que, em comparação com copolímeros em bloco para automontagem, exibem uma morfologia em nanoescala mais precisa em cada dimensão. ${ }^{46}$

Polímeros enxertados podem ser preparados por três estratégias principais: graft through (polimerização de macromonômeros), graft to (adição de cadeias laterais previamente preparadas à cadeia principal) e graft from (polimerização de cadeias laterais a partir de uma cadeia principal contendo um macroiniciador). ${ }^{47}$ Cada uma dessas estratégias controla diferentes parâmetros estruturais, incluindo composição química, densidade de enxerto, grau de polimerização das cadeias laterais e grau de polimerização da cadeia principal. Controlar esses parâmetros tem sido desafiador por causa do impedimento estérico na cadeia principal devido à alta densidade de enxertos. ${ }^{48}$

Entre as principais abordagens sintéticas que foram desenvolvidas, a de graft through tem sido utilizada para sintetizar os copolímeros enxertados via ROMP. Por exemplo, a síntese de partículas de látex obtidas por ROMP via dispersão, no qual 1,5-ciclo-octadieno e/ou NBE foram copolimerizados com NBE funcionalizado com PEG (polietilenoglicol). ${ }^{49,50}$ Em estudo posterior, as partículas de NBE funcionalizadas foram aplicadas como dispositivos de entrega de moléculas ativas, no caso a indometacina..$^{51}$

A síntese de uma série de polimacromonômeros, baseados em poliNBEs funcionalizados contendo vários grupos pendentes, foi obtida via ROMP repetitiva pela combinação de graft through-graft from. O macromonômero foi polimerizado via ROMP e o polímero resultante foi funcionalizado com o grupo norbornenil e polimerizado novamente via ROMP. Vários copolímeros anfifílicos ramificados foram preparados por esse método. ${ }^{52}$

A dificuldade de se obter a conversão completa e o controle preciso do tamanho da estrutura ramificada foram uma limitação para a homopolimerização de macromonômeros via ROMP. ${ }^{52}$ No entanto, quando a ROMP foi associada a outras técnicas, como, no caso, com a polimerização aniônica, polimacromonômeros foram preparados com conversão completa e com uma distribuição de massa molecular uniforme. Outro exemplo foi a combinação com ATRP usando-se um oxanorbornenil como grupo terminal, ${ }^{53}$ além de síntese em um estágio ROMP-ATRP.$^{54}$ Copolímeros enxertados bem definidos foram obtidos pela combinação da ROMP-ATRP pela estratégia graft through na síntese de derivados do poli(1,4-butadieno) com uma elevada densidade de funcionalidades pendentes. A estratégia proposta apresenta um polibutadieno exclusivamente linear, com uma microestrutura estritamente do tipo 1,4 e um controle exato sobre o posicionamento dos enxertos. ${ }^{55} \mathrm{Na}$ síntese de copolímeros de NBE e NBE funcionalizado com fosfoimina, polifosfazenos mono e telequélicos foram obtidos pela polimerização via ATRP, os quais foram funcionalizados com NBE e polimerizados via ROMP. ${ }^{56}$

\section{Polímeros em escova}

Copolímeros em escova é uma classe especial de copolímeros enxertados nos quais cadeias laterais são densamente distribuídas ao longo da cadeia principal do polímero. Por causa de seu arranjo aglomerado, as cadeias laterais ficam estendidas na cadeia principal produzindo uma arquitetura em escova. ${ }^{57,58}$ Esses copolímeros em escova com estruturas controladas fornecem um controle relativamente preciso da forma e do tamanho em cada dimensão, podendo gerar morfologias nanométricas que são inatingíveis por automontagem de copolímeros em bloco. ${ }^{46,59}$

A polimerização da maioria dos macromonômeros vinílicos é estericamente impedida. Por isso, a ROMP é uma alternativa atraente, onde macromonômeros geram um maior espaçamento entre as cadeias laterais, proporcionando um ambiente cineticamente mais favorável para as reações de propagação. ${ }^{60}$

Polimacromonômeros em escova foram preparados via ROMP a partir de um macromonômero contendo o grupo norbornenil, incluindo aqueles com cadeias de polilactida ${ }^{61} \mathrm{NBE}$-carboximida contendo uma funcionalidade amino protegida por $\mathrm{TMS}^{62}$ e polipeptídios. ${ }^{63}$ Esses polímeros foram obtidos com alta conversão e elevada massa molecular.

Mesmo que uma única estratégia de polimerização demonstre vantagens distintas em relação à arquitetura molecular, existem também limitações de síntese. Mais uma vez, a combinação de métodos permitiu a síntese de um polímero em escova com estrutura inalcançável por uma única técnica. ${ }^{64}$ Observou-se a síntese de copolímeros em escova contendo enxertos à base de homopolímeros pelo método graft from pela síntese em um estágio ROMP-ATRP. ${ }^{54}$ A síntese de copolímeros em escova via ROMP-RAFT foi obtida com facilidade devido à boa compatibilidade entre essas técnicas. ${ }^{65}$

A versatilidade na preparação desses polímeros também foi verificada em trabalhos que empregaram polimerizações ROMP-ATRP, ${ }^{66}$ ROMP-RAFT, ${ }^{65}$ ROMP-ROP-ATRP ${ }^{67}$ (Esquema 6) e ROMP-NMP ${ }^{68}$ para preparar uma série de polímeros em escova bem-definidos e, em alguns casos, em escova tipo caroço-casca. ${ }^{69}$

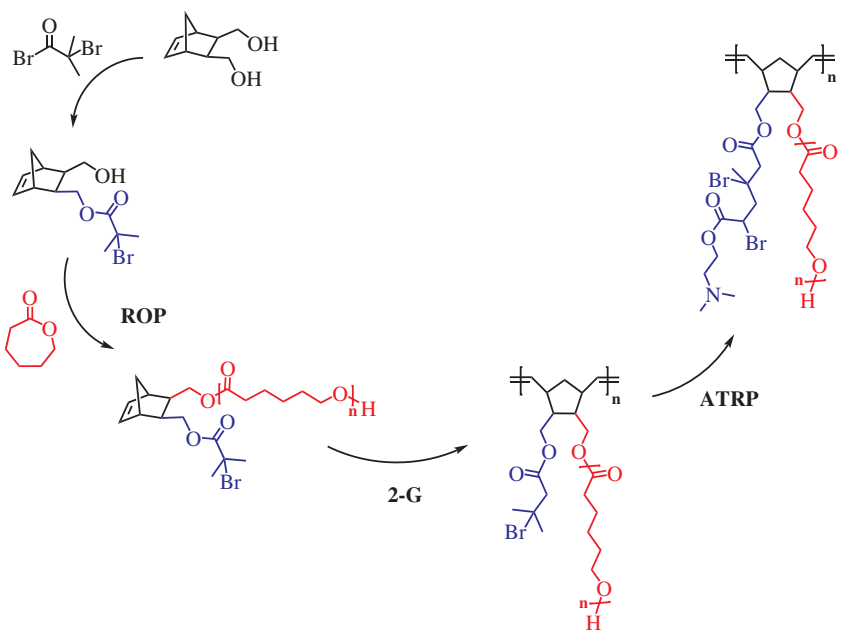

Esquema 6. Síntese de copolímeros com alta densidade de enxerto via ROMP-ROP-ATRP. Reproduzido da ref. 67, com permissão de American Chemical Society

\section{Polímeros estrela}

Copolímeros estrela têm despertado interesse devido à sua arquitetura única. ${ }^{70}$ Geralmente, iniciadores multifuncionais, agentes de ligações multifuncionais ou monômeros bifuncionais são utilizados na preparação desses polímeros com diferentes braços. ${ }^{71}$ Iniciadores multifuncionais são capazes de iniciar simultaneamente diversas polimerizações para formar os braços dos polímeros estrela, enquanto o restante da cadeia forma o núcleo da estrela.

PoliNBEs em forma de estrela foram obtidos via ROMP usando-se complexos dendríticos multinucleares de rutênio como catalisadores. ${ }^{72}$ Copolímeros estrela com três braços, homo $\left(\mathrm{A}_{3}\right)$ e heterobraços $\left(A_{3} B_{3}\right)$, empregando agentes de ligações multifuncionais vivos também foram obtidos por um método geral e eficiente. ${ }^{73}$

Um copolímero $\mathrm{AB}_{2}$ contendo açúcares protegidos foi preparado pelo acoplamento de PEG em um copolímero términofuncionalizado obtido via ROMP. ${ }^{12} \mathrm{O}$ método endcapping foi utilizado na 
preparação do terpolímero estrela ABC 3-miktoarm pela combinação da ROMP-ATRP-NMP e química click para atingir a estrutura alvo dos copolímeros. ${ }^{74}$

Um protocolo prático para a preparação de um novo copolímero estrela anfifílico $\mathrm{AB}_{2}$ foi desenvolvido por uma abordagem graft through-graft from, em combinação ROMP-ATRP. ${ }^{75} \mathrm{O}$ polímero à base de polioxaNBE monotelequélico foi preparado através de duas rotas diferentes (Esquema 7). O braço hidrofóbico com um grupo terminal dibromo foi utilizado como o macroiniciador de ATRP de 2-etil(dimetilamino) metacrilato para produzir dois braços hidrofílicos.

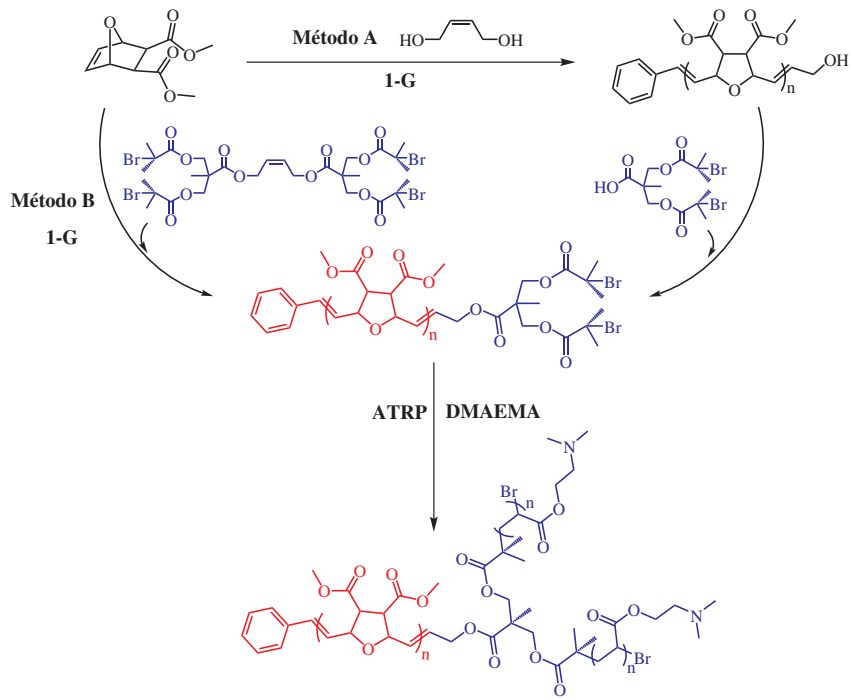

Esquema 7. Síntese do copolímero estrela $A B_{2}$ via ROMP-ATRP; DMAEMA = 2-etil(dimetilamino) metacrilato. Reproduzido da ref. 75 , com permissão da Elsevier

\section{POLÍMEROS BIOCOMPATÍVEIS}

A ROMP tem demonstrado ser uma ferramenta extremamente versátil para preparar bioconjugados poliméricos; ou seja, polímeros sintéticos com moléculas biológicas, tais como ácidos nucleicos, peptídios, proteínas, enzimas, carboidratos, etc. ${ }^{76,77}$ Esses polímeros já foram usados para modular respostas imunes in vivo na ativação de sinalização da célula B. ${ }^{78}$ Vários sistemas envolvendo poliNBEs funcionalizados ${ }^{79-81}$ e poli(fenileno-etinileno) $)^{82}$ também foram desenvolvidos e demonstraram atividade antimicrobiana contra diferentes subespécies de bactérias, incluindo subespécies multirresistentes. Em um destes trabalhos, foram sintetizados polímeros antimicrobianos onde variações sistemáticas da composição molecular, massa molecular e anfifilicidade foram otimizadas para gerar polímeros com maior seletividade e especificidade a bactérias em relação às células de mamíferos. ${ }^{80}$

Polímeros de NBE funcionalizados com peptídeos são ilustrados na Figura 2. ${ }^{81}$ Além de poliNBEs que exibem glicinas e alaninas pendentes, copolímeros com diferentes razões de segmento pendentes de Gli-Arg-Gli-Asp-Ser e Ser-Arg-Asn foram sintetizados com sucesso com massa molecular de aproximadamente $10-20 \mathrm{~kg} /$ mol e IPD entre 1,1 e 1,3. Os segmentos de peptídeos foram ligados diretamente ao NBE ou através de um sistema vinculador flexível. NBE funcionalizado com pentaetilenoglicol foi desenvolvido para melhorar a biocompatibilidade e reduzir a imunogenicidade, quando copolimerizado com monômeros biofuncionalizados.

Um mímico do domínio da fibronectina (glicoproteína que se liga à integrina, um receptor de proteínas) foi obtido pela copolimerização entre NBE-(Gli-Arg-Gli-Asp-Ser) e NBE-(Pro-His-Ser-Arg-Asn) ${ }^{82}$

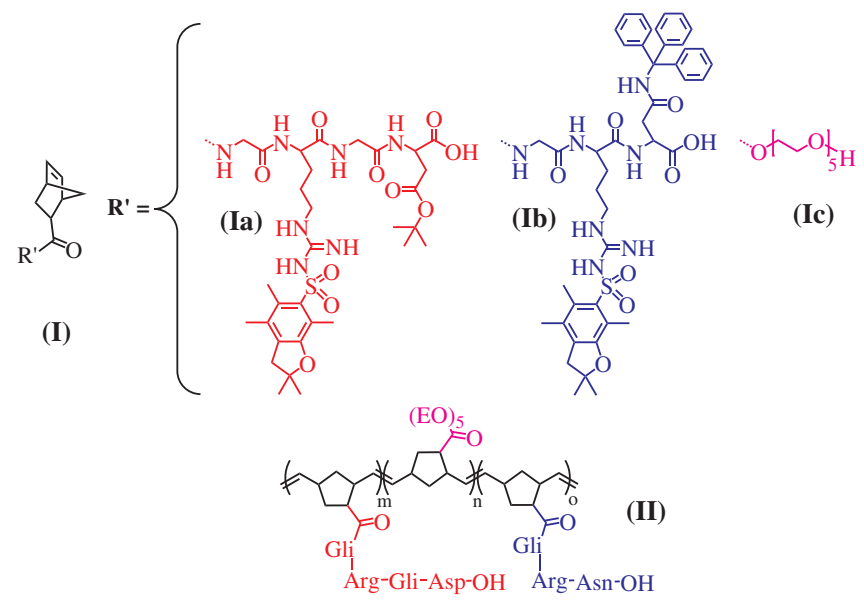

Figura 2. NBEs funcionalizados com o peptídeo (Gli-Arg-Gli-Asp-Ser) (Ia), com o peptídeo (Ser-Arg-Asn) (Ib) e com oligoetilenoglicol (Ic), e o respectivo terpolímero obtido via ROMP(II). Reproduzido da ref. 81, com permissão da American Chemical Society

Estes copolímeros são potentes inibidores da adesão celular à matriz extracelular da proteína fibronectina e mostraram uma atividade inibitória muito maior em comparação com a sequência livre Gli-Arg-Gli-Asp-Ser.

$\mathrm{Na}$ entrega de gene, veículos poliméricos não virais para a complexação de DNA e transfecção são de grande interesse devido à segurança e imunogenicidade quando comparados com a entrega mediada por vírus. ${ }^{83}$ Estudos relataram a síntese de vetores de entrega de DNA preparados pela copolimerização via ROMP de macromonômeros ciclo-octeno-oligosina com ciclo-octeno-PEG. Esses copolímeros foram competitivos frente a polímeros, dendrímeros e lipídios comerciais, tanto em termos de expressão da proteína quanto à viabilidade celular. ${ }^{84}$

A imagem molecular tem avançado significativamente em diagnóstico não invasivo de doenças. Recentemente, foi relatada a síntese de nanopartículas do tipo caroço-casca de copolímeros anfifílicos obtidos via ROMP, nos quais a superfície foi conjugada com anticorpos alvo de tumores. ${ }^{85}$

Ainda, copolímeros contendo corantes foram sintetizados via ROMP para visualização interna da celula in vitro ${ }^{86}$ Foi demonstrado que a ROMP, seguida pela reação de entrecruzamento, é uma ferramenta poderosa para a síntese de nanopartículas micelares de tamanhos ajustáveis. Isso propiciou a sua aplicação como sonda de tomografia de emissão de pósitrons para a imagem de tumor. ${ }^{87}$ Apesar de nenhuma aplicação de imagem in vivo ter sido divulgada, a síntese de copolímeros anfifílicos de tamanho controlado via ROMP foi considerada um dos mais promissores caminhos para a imagem de tumor in vivo e segmentação. ${ }^{88}$ Por outro lado, já foi demonstrado que o copolímero anfifílico à base de poliNBD contendo indocianina verde é uma sonda eficaz para imagem de tumor ${ }^{89} \mathrm{O}$ copolímero sintetizado através da ROMP e seguido pela di-hidroxilação das duplas ligações na cadeia se automontou. O polímero automontado apresentou um tempo de retenção longo no tecido tumoral, embora grandes quantidades da sonda também tenham se acumulado em tecidos normais, como o fígado. Isso é um exemplo da necessidade da síntese de novos monômeros biofuncionais e do desenvolvimento de metodologias para a obtenção de material pertinente.

A fim de evitar a retenção dos copolímeros automontados em tecidos normais, foi sintetizado um copolímero anfifílico em bloco contendo, na cadeia lateral, PEG, folato e uma molécula de indocianina verde como sonda, o qual foi aplicado para a imagem específica in vivo..$^{90}$ 
Com relação ao diagnóstico não invasivo, tem-se que a ROMP foi usada para desenvolver uma nova classe de copolímeros em bloco para a detecção biológica com a amplificação do sinal. Para isso, três monômeros foram sintetizados: monômeros luminescentes ou eletroquimioluminescentes contendo unidades de complexos polipiridínicos de rutênio, ósmio ou irídio; monômeros e macromonômeros biologicamente compatíveis contendo unidades de oligoetilenoglicóis e, monômeros contendo uma unidade de biorreconhecimento, a biotina. A polimerização via metátese permitiu combinar eficientemente esses monômeros em copolímeros anfifílicos di e triblocos que se automontaram em meio aquoso. ${ }^{91}$ Foram formados conjuntos micelares esféricos contendo núcleos luminescentes envoltos em uma casca protetora biocompatível e biologicamente inerte, e unidades de reconhecimento biológico ou grupos bioconjugáveis.

\section{POLÍMEROS DENDRONIZADOS}

Quando comparados aos tradicionais polímeros lineares ou ramificados, cadeias poliméricas dendronizadas adotam uma conformação mais rígida devido ao maior impedimento estérico. Essa característica os torna apropriados para o desenvolvimento de nanoarquiteturas capazes de complexar o DNA, ${ }^{92}$ de apresentar propriedades optoeletrônicas, ${ }^{93}$ de funcionar como sistemas de entrega de droga ${ }^{94}$ ou como suportes para catalisadores. ${ }^{95}$

A polimerização de NBE funcionalizado com unidades rígidas tipo bastão de terfenil como mesógenos formou um polímero dendronizado, com boa flexibilidade conformacional e comportamento líquido-cristalino (Figura 3). ${ }^{96} \mathrm{O}$ polímero apresentou transições de fase complexas, as quais foram associadas às duas escalas de tamanhos diferentes.

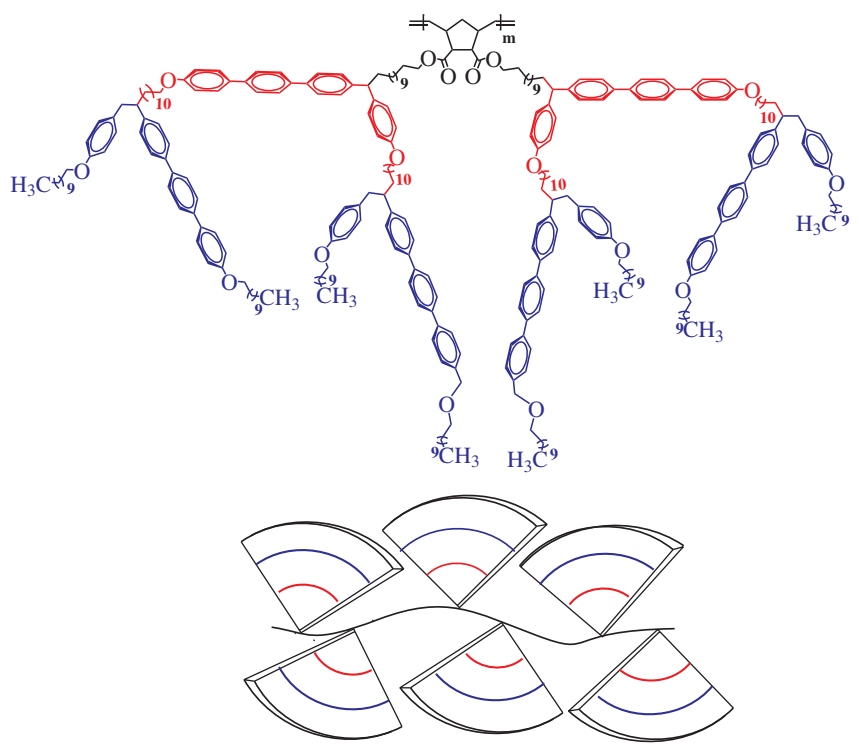

Figura 3. Polímero dendronizado obtido via ROMP de NBE funcionalizado com grupos terfenil. Reproduzido da ref. 96, com permissão da American Chemical Society

A síntese de copolímeros de NBEs dendronizados com unidades de NBEs funcionalizados com fulereno propiciaram a formação de polímeros semicondutores. ${ }^{97}$ Sabe-se que a organização de muitas estruturas de fulereno é essencial para a utilização do polímero como antenas ou nanofios semicondutores; porém, são insolúveis. Sendo assim, a inserção de um bloco anfifílico no polímero, no caso um dendrímero, propiciou um aumento considerável na solubilidade.

Uma série de polímeros dendronizados com diferentes grupos funcionais nas suas periferias já foi sintetizada com a finalidade de aplicação em membranas porosas. ${ }^{98}$ Com a diversidade de grupos funcionais nesse tipo de polímero, podem existir sítios ativos para reações e/ou modificações que ocorrem especificamente na superfície. Nesse mesmo caminho, as sínteses de copolímeros dendronizados diblocos podem exibir dois ramos funcionalizados com diferentes graus de complexidades. ${ }^{99}$

Com a proposta de desenvolver uma nova série de polímeros eletrofotoativos para fins de conversão de energia, copolímeros dendronizados dibloco com grupos azida foram funcionalizados com fulereno (receptor de elétrons) ou com porfirina (doador de elétrons) através da reação click $^{100} \mathrm{~A}$ estratégia foi obter polímeros à base de NBE com alta massa molecular e, então, modificar quimicamente os grupos azida. Isso permitiu a introdução de unidades de fulereno e porfirina, que são duas funções importantes para a construção de materiais fotovoltaicos.

\section{POLÍMEROS FOTOATIVOS}

O desenvolvimento de sensores fotossensíveis tem sido vinculado ao desenvolvimento de uma matriz compatível com sua aplicação. ${ }^{101,102}$ Assim, o desenvolvimento de polímeros que apresentem grupos cromóforos em circunstâncias de fotossensibilidade controlada é de especial interesse para aplicação científica e tecnológica em várias áreas da ciência. ${ }^{103-105}$

Diversos polímeros obtidos a partir de olefinas cíclicas funcionalizadas com ésteres ou amidas que mostram fotoatividade, ou de copolímeros contendo grupos cromóforos em sistemas anfifílicos, foram obtidos via ROMP. Um exemplo é o copolímero tribloco formado com NBEs funcionalizados com unidades de metiléster, etilenoglicol e corante xantona sofrendo automontagem em metanol. ${ }^{103}$ Em outro trabalho, foi obtida uma resposta óptica do grupo fenantroimidazol em função do meio ácido ou básico. ${ }^{102}$ A característica de emissão desse grupo foi modificada pela substituição do átomo de hidrogênio (monômero 1) por um grupo metil (monômero 2) no nitrogênio terciário do anel imidazol. Posteriormente copolimerizados com um éster derivado de NBE (monômero 3), a emissão dos copolímeros também foi influenciada pela substituição do hidrogênio pelo grupo metil (Esquema 8). Enquanto as propriedades fotofísicas de $\mathbf{1}$ foram modificadas quando copolimerizados, 2 e o respectivo copolímero poli2/3 apresentaram as mesmas características de absorção e emissão.

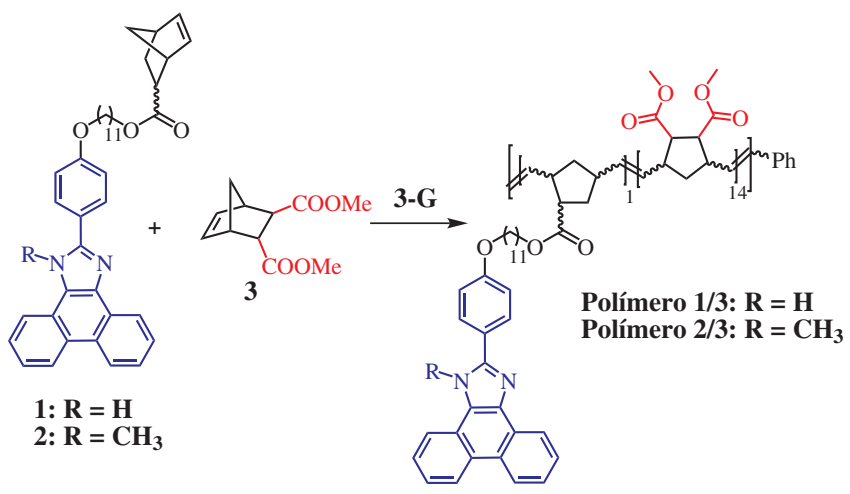

Esquema 8. Sínteses via ROMP de copolímeros contendo o grupo cromóforo fenantroimidazol. Reproduzido da ref. 102, com permissão da Elsevier

Em outro trabalho, foram estudadas as propriedades de cromóforos obtidos pela reação entre a xantona e derivados de NBE. ${ }^{105} \mathrm{O}$ monômero cromóforo foi usado para a preparação de copolímeros com ácido endo,exo-2,3-NBE dicarboxílico dimetiléster, sendo as características de absorção e luminescência e o comportamento ácido/ 
base do cromóforo precursor preservados no copolímero. A absorção e emissão máxima em THF e no estado sólido foram na região do vermelho em comparação com o cromóforo precursor. A facilidade da síntese desses compostos, aliada à alta tolerância dos catalisadores de rutênio a diversos grupos funcionais, permitiu uma eficiente abordagem para uma grande diversidade de materiais poliméricos. ${ }^{105}$

Metais de transição incorporados em polímeros podem formar materiais fotoativos quando monômeros são funcionalizados com grupos capazes de atuarem como ligantes e formarem complexos de coordenação luminescentes. ${ }^{104}$ Ainda, essa característica pode ser seletiva em função do meio. Por exemplo, a síntese de um copolímero constituído de NBEs funcionalizados com metiléster, etilenoglicol e com os grupos cromóforos de um derivado do carbazol e de um complexo de platina(II). Quando o polímero foi dissolvido em um solvente seletivo (metanol), observou-se uma coloração vermelha relativa ao complexo de platina. Entretanto, em um solvente não seletivo (clorofórmio), a propriedade de emissão foi determinada pelo derivado carbazol, onde apenas a emissão azul foi observada. Dessa forma, a arquitetura do copolímero em função do meio é decisiva para a seletividade da emissão do cromóforo.

Propriedades fotocrômicas de vários polímeros obtidos a partir do 1,2-bis(3-tienil)ciclopenteno e indolina-benzoespiropirano em solução mantiveram as propriedades dos monômeros cromóforos e foram solúveis em solventes orgânicos. ${ }^{106,107}$ Uma série de copolímeros com diferentes grupos cromóforos exibe um completo espectro de cores, que pode ser usado na tecnologia de displays. ${ }^{108}$

A utilização da ROMP com outras técnicas para a obtenção de polímeros fotoativos, tais como a ATRP, pode também proporcionar a obtenção de um copolímero de NBE com um grupo cromóforo. ${ }^{109}$ $\mathrm{O}$ copolímero contendo um grupo cromóforo e um grupo $\mathrm{CH}_{2} \mathrm{Br}$ foi posteriormente polimerizado por ATRP com metilmetacrilato, o que resultou em forte emissão entre 370 e $450 \mathrm{~nm}$. Esse material pode ser utilizado como dispositivos eletrônicos moleculares.

\section{POLÍMEROS RETICULADOS}

Polímeros reticulados podem apresentar vantagens importantes sobre os polímeros lineares por apresentarem melhores propriedades mecânicas, químicas e térmicas e menor dependência da temperatura sobre a viscosidade. ${ }^{110} \mathrm{O}$ entrecruzamento nos materiais poliméricos é formado por ligações covalentes entre as cadeias a partir de agentes de cura, radicais formados por irradiação ou pelo uso de monômeros multifuncionais. ${ }^{110}$

Monômeros com diferentes graus de complexidade foram obtidos a partir do NBD, o qual é capaz de realizar entrecruzamento via ROMP. ${ }^{111}$ Misturando-se os agentes de reticulação aos monômeros DCPD (diciclopentadieno) ou ENB (2-NBE-5-etilideno), as propriedades dos polímeros resultantes foram modificadas, promovendo um aumento da $T_{\mathrm{g}}$ de 150 para $169^{\circ} \mathrm{C}$ com poliDCPD e de 114 para $126^{\circ} \mathrm{C}$ com poliENB. Outra investigação realizada foi a do uso de um monômero capaz de agir como agente de reticulação para modificar as propriedades de polímeros que são utilizados como agentes de autocura (DCPD ou ENB). ${ }^{112}$ Neste caso, testes de entumecimento e análises dos módulos de armazenamento nas regiões vítrea e borrachosa foram utilizados para avaliar o grau de entrecruzamento, o qual aumentou com o aumento da alimentação de agente de entrecruzamento, confirmando a formação de um material altamente reticulado. Recentemente, o atrito e o comportamento de desgaste desses sitemas (DCPD com agentes de reticulação misturados) foram avaliados em função da densidade de ligações cruzadas por medidas tribológicas. ${ }^{113}$ $\mathrm{O}$ aumento na densidade de reticulação nesses materiais poliméricos melhorou ligeiramente a resposta ao atrito e os tornou mais resistentes ao desgaste abrasivo.
As propriedades térmicas de poliNBE sintetizado via ROMP foram melhoradas quando NBE foi copolimerizado com diferentes quantidades de NBD, o qual atuou como agente de entrecruzamento (Esquema 9). ${ }^{114} \mathrm{O}$ grau de entrecruzamento nos copolímeros aumentou com o acréscimo da quantidade de NBD, elevando os valores de $T_{\mathrm{g}}$ de 37,0 para $62,0^{\circ} \mathrm{C}$. Além de favorecer a formação de um polímero entrecruzado, NBD propiciou que as espécies propagantes crescessem de maneira mais uniforme reduzindo os valores de IPD de 1,52 para 1,26, agindo como um agente regulador de cadeia. Em outro estudo, poli[NBE-co-NBD] foi obtido variando-se a fração molar dos monômeros. ${ }^{115}$ Testes de entumecimento mostraram que diferentes graus de entrecruzamento ocorreram em função da fração molar, resultando em polímeros com diferentes solubilidades. Esses copolímeros têm potencial aplicativo como agentes de cura.

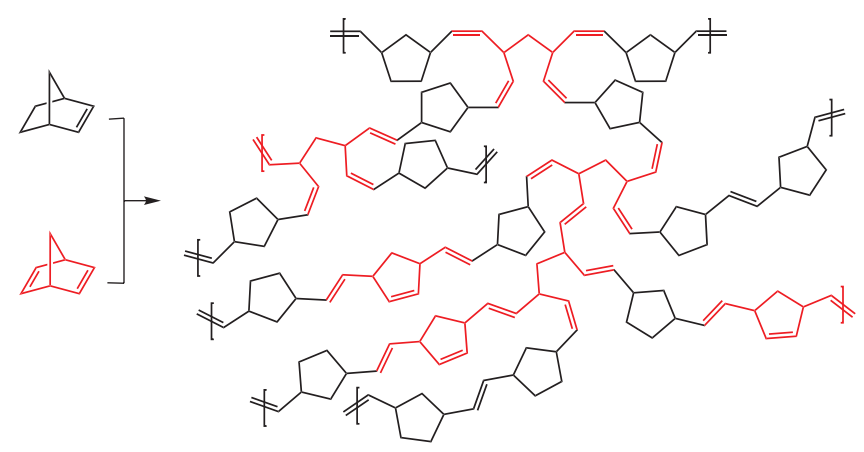

Esquema 9. Copolímeros de NBE e NBD via ROMP para formar uma estrutura entrecruzada

Uma série de monômeros imidoNBE monofuncionalizados também foram sintetizados e, posteriormente, copolimerizados com monômeros difuncionalizados, obtendo-se materiais com alto grau de reticulação. ${ }^{116}$ No desenvolvimento de novos monômeros que agem como agentes de reticulação, polímeros à base de poliNBE dicarboximida entrecruzados através de ligações de ésteres de acetal foram obtidos. ${ }^{117}$ Estudos do comportamento da degradação térmica desses materiais ilustraram que ocorre primeiro o rompimento térmico das ligações cruzadas, mantendo a cadeia principal intacta. Isso permite a transição de termorrígido para termoplástico, o que facilita a reciclagem.

A combinação da reação de ROMP com um sistema de entrecruzamento dirradicalar proporcionou um novo método para o desenvolvimento de um biomaterial com altíssima dureza e com potencial para ser utilizado como osso artificial. ${ }^{118}$ Neste caso, inicialmente obtiveram-se polímeros lineares flexíveis com grupos pendentes apresentando funções diazo fotorreativas. Após a irradiação do polímero, dois processos foram observados: primeiro, ocorreu a eliminação de $\mathrm{N}_{2}$ gerando uma porosidade desejável e, em seguida, os dirradicais provocaram a formação de ligações cruzadas entre as cadeias lineares que endureceram o material.

Aliando-se tipos de reações diferentes, polímeros obtidos via ROMP términofuncionalizados com grupos diazo reagiram por processos do tipo click para sintetizar uma rede polímerica líquido-cristalina com cadeias laterais bem definidas. Assim, os entrecruzamentos das cadeias foram realizados através da reação click de polímeros telequélicos obtidos via ATC. ${ }^{119}$

Neoglicopolímeros foram investigados como novos agentes de reticulação de colágeno na engenharia de tecido da córnea. ${ }^{120}$ Para tanto, neoglicopolímeros saturados foram preparados pela combinação ROMP-hidrogenação de NBE funcionalizado com carboidratos. Esses polímeros foram incorporados em um colágeno humano 
recombinante como agentes de reticulação de colágeno e miméticos de glicosaminoglicanos.

Embora os métodos de entrecruzamento por ligações covalentes sejam bem sucedidos, frequentemente são irreversíveis e não são totalmente controlados, o que limita, muitas vezes, a extensão da ligação cruzada. A falta de controle pode resultar na perda de propriedades importantes que sejam inerentes aos polímeros como, por exemplo, a termoplasticidade. ${ }^{110}$

Uma estratégia de entrecruzamento em polímeros por funcionalização sem o uso de ligações covalentes permite a síntese de materiais reticulados de maneira rápida e controlada, superando muitos dos problemas dos polímeros entrecruzados formados por meio de uma ligação covalente. A copolimerização de monômeros funcionalizados e o entrecruzamento dos grupos pendentes em uma única etapa podem ocorrer via ROMP. ${ }^{121}$ Assim, terpolímeros aleatórios foram sintetizados a partir de monômeros funcionalizados com cadeias alquilas, com complexos paladatados e com grupos diaminopiridina ou cianúricos. O entrecruzamento ocorreu com a adição de agentes de cura seletivos por meio de ligação coordenada ou ligação de hidrogênio.

\section{AUTOCURA VIA ROMP}

Materiais poliméricos autocuráveis possuem a capacidade intrínseca de se recuperarem após um dano. A restauração pode ocorrer de maneira autônoma ou ativada após a aplicação de um estímulo específico (por exemplo, temperatura ou irradiação). A principal vantagem é o aumento da durabilidade dos componentes poliméricos, evitando gastos com monitoramento ou reparo externo. Um material de autocura ideal é capaz de responder continuamente a danos durante a vida útil dos componentes poliméricos, restaurando a função do material sem alterar suas propriedades iniciais. Isso permite a síntese de materiais mais confiáveis e duráveis, com a redução de custos de manutenção. ${ }^{122}$

A microencapsulação é um dos conceitos mais estudados no desenvolvimento de materiais autocuráveis. Vários sistemas já foram investigados e observa-se que o sistema de autocura baseado na reação de ROMP tem atraído muita atenção. ${ }^{123-128}$ Esta abordagem envolve a incorporação de um agente de cura microencapsulado e um catalisador disperso em uma matriz polimérica. ${ }^{123}$ Após a lesão induzida pelas rachaduras, as microcápsulas são rompidas pelas fissuras resultando na liberação do agente de cura por ação capilar. Então, a polimerização do material, reação química entre o agente de cura e o catalisador, ocorre impedindo o crescimento da rachadura (Figura 4). ${ }^{123}$

As microcápsulas devem possuir resistência suficiente para permanecerem intactas durante o processamento do polímero,

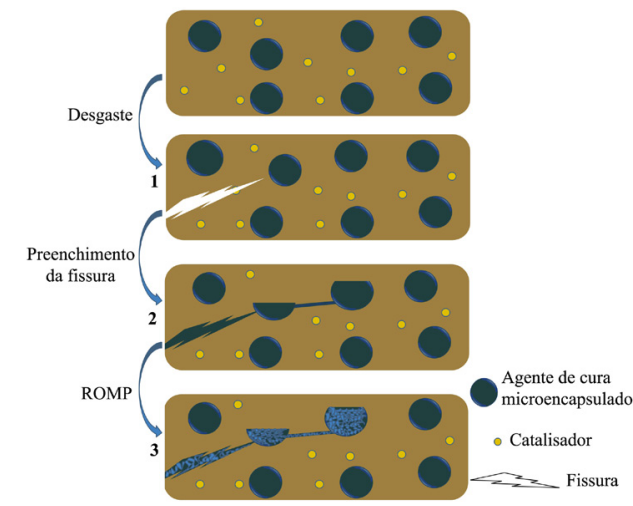

Figura 4. Ilustração do fenômeno de autocura: (1) formação da fissura na matriz polimérica; (2) rompimento da microcápsula liberando o agente de cura na fissura; (3) polimerização via ROMP do agente de cura após o contato com o catalisador incorporado na matriz. Adaptado da ref. 123, com permissão da American Chemical Society rompendo-se somente no local da fissura. Estas também devem ser capazes de liberar os agentes de cura e/ou os catalisadores dentro da rachadura, além de possuírem o mínimo de efeitos adversos sobre as propriedades da matriz polimérica. Dessa forma, um sistema de autocura adequado precisa possuir as características de ser facilmente encapsulado, manter-se estável e ativo ao longo da vida útil dos componentes poliméricos sob condições ambientes, e responder rapidamente à reparação de danos, uma vez provocado.

O sistema de autocura mais bem sucedido e extensivamente investigado compreende a ROMP de diciclopentadieno. ${ }^{123-126}$ É absolutamente essencial que o processo de cura ocorra à temperatura ambiente ou menor, e que a viscosidade do agente seja baixa o suficiente para encher as rachaduras completamente antes da polimerização. ${ }^{123}$

PoliDCPD apresenta alta tenacidade, alcançada pela formação de uma estrutura reticulada. Porém, endo-DCPD apresenta uma velocidade de polimerização in situ lenta. Uma abordagem para contornar esse problema foi a utilização de exo-DCPD, o qual possibilita uma cinética de polimerização muito mais rápida devido a uma diminuição do impedimento estérico e a uma possível dupla coordenação da forma endo ao centro metálico. ${ }^{129}$

Uma outra dificuldade de aplicação do DCPD como agente de cura reticulante a baixas temperaturas é o seu ponto de fusão de $33{ }^{\circ} \mathrm{C}$. Dessa forma, a utilização de ENB foi uma alternativa como agente de cura. Este monômero combina uma elevada reatividade na polimerização e um baixo ponto de fusão $\left(-80^{\circ} \mathrm{C}\right)$. No entanto, ao contrário do DCPD, o ENB não forma um polímero reticulado, possuindo propriedades mecânicas inferiores. Portanto, foram estudadas misturas de ENB com um reticulador à base de NBE, observando-se o aumento do grau de entrecruzamento com o aumento do agente reticulante. ${ }^{112}$

É importante ressaltar que, para a otimização do processo de autocura via ROMP, muitos estudos têm sido realizados quanto às variáveis do processo de microcapsulação, ${ }^{124,130}$ da quantidade ideal de monômero microencapsulado para a máxima eficiência de cura, ${ }^{131}$ da interação do catalisador com a matriz, ${ }^{125}$ da encapsulação do catalisador ${ }^{126}$ e de sistemas de catalisadores alternativos. ${ }^{132}$

\section{POLÍMEROS A PARTIR DE FONTES RENOVÁVEIS}

Óleos vegetais têm sido bastante usados na química de polímeros por conta da sua natureza renovável, baixo custo e facilidade de transformação. Vários exemplos podem ilustrar polímeros sintetizados a partir de óleos naturais. ${ }^{133-139}$ Os processos de polimerização podem ocorrer no próprio triglicerídeo, que é a principal matéria-prima dos óleos, ou nos seus derivados obtidos por transesterificação. A polimerização via metátese destaca-se como meio de obtenção de polímeros oriundos desses compostos por propiciar reações mais controladas, resultando em produtos com características desejadas. ${ }^{133-138}$

A inserção de dois ou mais derivados de NBE como agentes de reticulação na estrutura de um triglicerídeo atraiu a atenção no desenvolvimento de novos materiais a partir de fontes renováveis. ${ }^{140}$ Um exemplo de ROMP a partir de fontes renováveis foi a síntese de derivados de NBE com ácidos graxos saturados com tamanho de cadeia de 6 a 18 átomos de carbono, que resultou em polímeros com estreita distribuição de massa (IPD = 1,05 a 1,26) e com boa estabilidade térmica. ${ }^{134}$ Foi demonstrado que à medida que aumenta o tamanho desse grupo pendente, a $T_{\mathrm{g}}$ dos polímeros diminui (102 a $-32{ }^{\circ} \mathrm{C}$ ), bem como o rendimento de reação devido ao impedimento estérico.

O Dilulin ${ }^{\circledR}$ é um triglicerídeo modificado a partir do óleo de linhaça pela incorporação de ciclopentadieno em uma das suas insaturações. A ROMP entre o ciclopentadieno e um NBE funcionalizado com um éster de 9 carbonos, o qual atuou como um agente 
reticulante, resultou em polímeros com grande quantidade de ligações cruzadas. ${ }^{136} \mathrm{~A} T_{\mathrm{g}}$ do copolímero diminui de 11,6 para $-17,4{ }^{\circ} \mathrm{C}$, bem como a temperatura de degradação, conforme aumenta a quantidade do NBE funcionalizado.

Através dos grupos hidroxilas existentes no óleo de rícino, foram obtidos monômeros derivados de NBE, tanto no triglicerídeo quanto no álcool derivado (Esquema 10). Os materiais obtidos via ROMP apresentaram boa estabilidade térmica com altos valores de $T_{\mathrm{g}} \mathrm{e}$ grande densidade de ligações cruzadas, variando de 318 para 6028 $\mathrm{mol} / \mathrm{m}^{3}$. A melhora nas propriedades foi obtida ao se variar a razão entre o monômero sintetizado a partir do triglicerídeo e o sintetizado a partir do álcool derivado. ${ }^{137}$ No mesmo sentido, o comportamento de cura e as propriedades viscoelásticas de um monômero de NBE inserido no óleo de linhaça foram capazes de agir como um agente de reticulação (bis-NBD). ${ }^{140}$

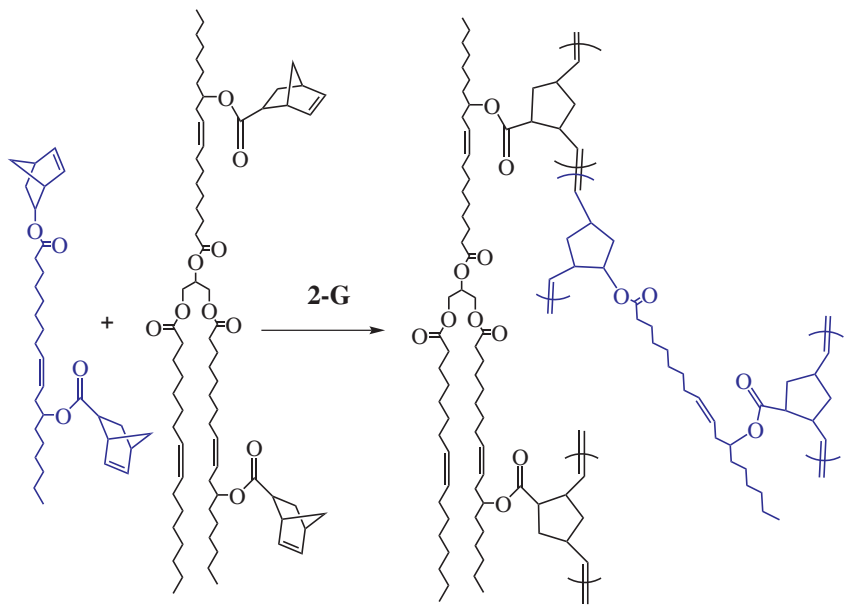

Esquema 10. Copolimerização via ROMP de NBE funcionalizado com óleo de rícino. Reproduzido da ref. 137, com permissão da Elsevier

A ROMP de diversos monômeros de diferentes ácidos graxos com 5-NBE-2,3-carboxilato já foi realizada. Os materiais termorrígidos tiveram suas propriedades influenciadas pelos diferentes grupos existentes nos ácidos graxos. ${ }^{141}$ As diferentes estruturas nas cadeias deram origem a materiais com diferentes aparências e propriedades. Os polímeros sintetizados a partir dos alcoóis derivados dos triglicerídeos de Dilulin ${ }^{\circledR}$, ML 189 e óleo de soja apresentaram menor grau de solubilidade, maior estabilidade térmica e melhores propriedades mecânicas que o polímero sintetizado a partir do álcool derivado do óleo de mamona.

A ADMET (polimerização via metátese de dienos acíclicos) também é uma forma de obtenção de polímeros via metátese bastante utilizada na química de materiais sintetizados a partir de fontes renováveis, ${ }^{133}$ obtendo-se polímeros com altas massas moleculares. ${ }^{142}$ Tem-se demonstrado que a etenólise de muitos ésteres de ácidos graxos via ADMET forma uma variedade de materiais poliméricos interessantes. Por exemplo, poliésteres com alta massa molecular do tipo tribloco foram obtidos por ADMET de óleos de plantas modificados, utilizando-se 10-undecenoato de metila como agente terminador para controlar o tamanho da cadeia. ${ }^{143}$

\section{CONCLUSÃO}

Os resultados apresentados aqui demonstraram que as reações via ROMP têm permitido a síntese de polímeros com estruturas moleculares bem definidas ou que sejam complicadas de serem atingidas por outra metodologia. Foi ilustrado que ROMP é uma metodologia eficiente para síntese de (co)polímeros com características anfifílicas (seja do tipo em bloco, enxertado, em escova ou estrela), biocompatíveis, fotoativas, dendronizadas ou reticuladas. Também foram ilustrados sistemas para autocura e polímeros obtidos a partir de fontes renováveis. Pode-se dizer que se trata de um método versátil e que pode ser aplicado para muitas finalidades, podendo ser combinado com muitos outros tipos de reações de polimerização bem estabelecidas. Muitos outros exemplos podem ser encontrados na literatura, ${ }^{2,3,7}$ e a diversidade de uso dessa metodologia tem aumentado extremamente. Recentemente, pode-se observar o desenvolvimento de polímeros para aplicações em permeação de gás, como materiais eletrocrômicos, em colunas cromatográficas, bem como na preparação de nanopartículas poliméricas funcionalizadas. ${ }^{144-147}$

No entanto, não se pode deixar de lembrar que ainda existem desafios a serem vencidos quanto à capacidade de controlar a estereoquímica dos polímeros com precisão e a reatividade dos catalisadores que podem provocar reações secundárias intra ou intermoleculares do tipo backbiting ou reações com ATC. Para tanto, a continuidade desse sucesso está atrelado ao contínuo desenvolvimento de catalisadores. ${ }^{7-11,148,149}$

\section{AGRADECIMENTOS}

Às agências de fomento CAPES, CNPq e FAPESP por concessões de bolsas de estudos e suporte concedido. Ao Prof. D. F. Menezes pela revisão ortográfica.

\section{LISTA DE ABREVIAÇÕES}

ADMET: Polimerização via metátese de dienos acíclicos (acyclic diene metathesis polymerization)

AT: Agente de terminação

ATC: Agente de transferência de cadeia

ATRP: Polimerização radicalar por transferência de átomo (atom transfer radical polymerization)

DCPD: Diclopentadieno

DNA: Ácido desoxirribonucleico

ENB: 5-Etilideno-2-norborneno

IPD: Índice de polidispersidade

NBD: Norbornadieno

NBE: Norborneno

NMP: Polimerização mediada por nitróxido (nitroxide-mediated polymerization)

PEG: Polietilenoglicol

RAFT: Polimerização por transferência de cadeia reversível por adição-fragmentação (reversible addition-fragmentation chain transfer polymerizaton)

ROMP: Polimerização via metátese de olefinas cíclicos por abertura de anel (ring opening metathesis polymerization)

ROP: Polimerização por abertura de anel (ring opening polymerization) THF: Tetra-hidrofurano

TMS: Tetrametilsilano

\section{REFERÊNCIAS}

1. Ivin, K. J.; Mol, J. C.; Olefin metathesis and metathesis polymerization, Academic Press: New York, 1997.

2. Grubbs, R. H.; Handbook of metathesis, Wiley-VCH: Weinheim, 2003.

3. Leitgeb, A.; Wappel, J.; Slugovc, C.; Polymer 2010, 51, 2927.

4. Michrowska, A.; Gułajski, L.; Kaczmarska, Z.; Mennecke, K.; Kirschning, A.; Grela, K.; Green Chem. 2006, 8, 685.

5. Mol, J. C.; J. Mol. Catal. A: Chem. 2004, 213, 39.

6. Chauvin, Y.; Angew. Chem., Int. Ed. 2006, 45, 3741.

7. Bielawski, C. W.; Grubbs, R. H.; Prog. Polym. Sci. 2007, 32, 1. 
8. Samojłowicz, C.; Bieniek, M.; Grela, K.; Chem. Rev. 2009, 109, 3708.

9. Vougioukalakis, J.; Grubbs, R. H.; Chem. Rev. 2010, 110, 1746.

10. Schrock, R. R.; Dalton Trans. 2011, 40, 7484.

11. Sutthasupa, S.; Shiotsuki, M.; Sanda, F.; Polym. J. 2010, 42, 905.

12. Murphy, J. J.; Kawasaki, T.; Fujiki, M.; Nomura, K.; Macromolecules $\mathbf{2 0 0 5}, 38,1075$.

13. Cheng, G.; Hua, F.; Melnichenko, Y. B.; Hong, K.; Mays, J. W.; Hammouda, B.; Wignall, G. D.; Eur. Polym. J. 2008, 44, 2859.

14. Hilf, S.; Kilbinger, A. F. M.; Nat. Chem. 2009, 1, 537.

15. Castle, T. C.; Hutchings, L. R.; Khosravi, E.; Macromolecules 2004, 37, 2035.

16. Owen, R. M.; Gestwicki, J. E.; Young, T.; Kiessling, L. L.; Org. Lett. 2002, 4, 2293.

17. Matson, J. B.; Virgil, S.C.; Grubbs, R. H.; J. Am. Chem. Soc. 2009, 131, 3355 .

18. Matson, J. B.; Grubbs, R. H.; Macromolecules 2010, 43, 213.

19. Mahanthappa, M. K.; Bates, F. S.; Hillmyer, M. A.; Macromolecules 2005, 38, 7890.

20. Hilf, S.; Kilbinger, A. F. M.; Macromolecules 2009, 42, 1099.

21. Olsen, B. D.; Segalman, R. A.; Mater. Sci. Eng. R. 2008, 62, 37.

22. Hamley, I.; Block copolymers in solution: fundamentals and applications, John Wiley \& Sons Ltd.: England, 2005.

23. Liu, C. L.; Lin, C. H.; Kuo, C. C.; Lin, S. T.; Chen, W. C.; Prog. Polym. Sci. 2011, 36, 603.

24. Baradie, B.; Shoichet, M. S.; Macromolecules 2002, 35, 3569.

25. Lele, B. S.; Leroux, J. C.; Macromolecules 2002, 35, 6714.

26. Liaw, D. J.; Huang, C. C.; Wu, P. L.; Polymer 2001, 42, 9371.

27. Lim, Y. B.; Moon, K. S.; Lee, M.; J. Mater. Chem. 2008, 18, 2909.

28. Eren, T.; Tew, G. N.; J. Polym. Sci. Part A: Polym. Chem. 2009, 47, 3949.

29. Stubenrauch, K.; Moitzi, C.; Fritz, G.; Glatter, O.; Trimmel, G.; Stelzer, F.; Macromolecules 2006, 39, 5865.

30. Stubenrauch, K.; Voets, I.; Fritz-Popovski, G.; Trimmel, G.; J. Polym. Sci. Part A: Polym. Chem. 2009, 47, 1178.

31. Ahmed, S. R.; Bullock, S. E.; Cresce, A. V.; Kofinas, P.; Polymer 2003, 44, 4943.

32. Akcora, P.; Briber, R. M.; Kofinas, P.; Polymer 2009, 50, 1223.

33. Radano, C. P.; Scherman, O. A.; Stingelin-Stutzmann, N.; Muller, C.; Breiby, D. W.; Smith, P.; Janssen, R. A. J.; Meijer, E. W.; J. Am. Chem. Soc. 2005, 127, 12502.

34. Boudouris, B. W.; Frisbie, C. D.; Hillmyer, M. A.; Macromolecules 2008, $41,67$.

35. Miyamot, Y.; Fujiki, M.; Nomura, K.; J. Polym. Sci. Part A: Polym. Chem. 2004, 42, 4248.

36. Ding, L.; Zhang, L.; Yang, D.; Huang, Wei.; Xie, M.; Zhang, Y.; Polymer 2010, 51, 1285

37. Xie, M.; Kong, Y.; Han, H.; Shi, J.; Ding, L.; Song, C.; Zhang, Y.; React. Funct. Polym. 2008, 68, 1601.

38. Bernaerts, K. V.; Prez, F. E. D.; Prog. Polym. Sci. 2006, 31, 671.

39. Notestein, J. M.; Lee, L. B. W.; Register, R. A.; Macromolecules 2002 , $35,1985$.

40. Wang, Y. Q.; Noga, D. E.; Yoon, K.; Wojtowicz, A. M.; Lin, A. S. P.; García, A. J.; Collard, D. M.; Weck, M.; Adv. Funct. Mater. 2008, 18, 3638.

41. Chen, L.; Phillip, W. A.; Cussler, E. L.; Hillmyer, M. A.; J. Am. Chem. Soc. 2007, 129, 13786

42. Ma, J.; Cheng, C.; Wooley, K. L.; Aust. J. Chem. 2009, 62, 1507.

43. Gao, H. F.; Matyjaszewski, K.; J. Am. Chem. Soc. 2007, 129, 6633.

44. Kluger, C.; Binder, W. H.; J. Polym. Sci. Part A: Polym. Chem. 2007, 45, 485.

45. Hadjichristidis, N.; Pispas, S.; Pitsikalis, M.; Iatrou, H.; Lohse, D. J.; Graft copolymers, Encyclopedia of Polymer Science and Technology, John Wiley \& Sons, Inc.: New York, 2004.
46. Lord, S. J.; Sheiko, S. S.; LaRue, I.; Lee, H. I.; Matyjaszewski, K.; Macromolecules 2004, 37, 4235.

47. Matyjaszewski, K.; Gnanou, Y.; Leibler, L.; Macromolecular engineering: precise synthesis, materials properties, applications, Wiley- $\mathrm{VCH}$ : Weinheim, 2007.

48. Sheiko, S. S.; Sumerlin, B. S.; Matyjaszewski, K.; Prog. Polym. Sci. 2008, 33, 759 .

49. Chemtob, A.; Héroguez, V.; Gnanou, Y.; J. Polym. Sci. Part A: Polym. Chem. 2004, 42, 2705.

50. Chemtob, A.; Héroguez, V.; Gnanou, Y.; J. Polym. Sci. Part A: Polym. Chem. 2004, 42, 1154.

51. Quémener, D.; Héroguez, V.; Gnanou, Y.; J. Polym. Sci. Part A: Polym. Chem. 2005, 43, 217.

52. Nomura, K.; Takahashi, S.; Imanishi, Y.; Macromolecules 2001, 34, 4712.

53. Czelusniak, I.; Khosravi, E.; Kenwright, A. M.; Ansell, C. W. G.; Macromolecules 2007, 40, 1444.

54. Cheng, C.; Khoshdel, E.; Wooley, K. L.; Nano Lett. 2006, 6, 1741.

55. Morandi, G.; Piogé, S.; Pascual, S.; Montembault, V.; Legoupy, S.; Fontaine, L.; Mater. Sci. Eng., C 2009, 29, 367.

56. Allcock, H. R.; de Denus, Christine R.; Prange, R.; Laredo, W. R.; Macromolecules 2001, 34, 2757.

57. Zhang, Z. B.; Shi, Z. Q.; Han, X.; Holdcroft, S.; Macromolecules 2007, 40, 2295.

58. Zamurovic, M.; Christodoulou, S.; Vazaios, A.; Iatrou, E.; Pitsikalis, M.; Hadjichristidis, N.; Macromolecules 2007, 40, 5835.

59. Boyce, J. R.; Shirvanyants, D.; Sheiko, S. S.; Ivanov, D. A.; Qin, S.; Borner, H.; Matyjaszewski, K.; Langmuir 2004, 20, 6005.

60. Cheng, C.; Khoshdel, E.; Wooley, K. L.; Macromolecules 2005, 38, 9455 .

61. Jha, S.; Dutta, S.; Bowden, N. B.; Macromolecules 2004, 37, 4365.

62. Lu, H.; Cheng, J.; J. Am. Chem. Soc. 2007, 129, 14114.

63. Lu, H.; Cheng, J.; J. Am. Chem. Soc. 2008, 130, 12562.

64. Mijović, J.; Sun, M.; Pejanović, S.; Mays, J. M.; Macromolecules 2003 , 36,7640 .

65. Cheng, C.; Khoshdel, E.; Wooley, K. L.; Macromolecules 2007, 40, 2289.

66. Cheng, C.; Khoshdel, E.; Wooley, K. L.; Macromolecules 2006, 6, 1741.

67. Xie, M.; Dang, J.; Han, H.; Wang, W.; Liu, J.; He, X.; Zhang, Y.; Macromolecules 2008, 41, 9004.

68. Cheng, C.; Qi, K.; Khoshdel, E.; Wooley, K. L.; J. Am. Chem. Soc. 2006, 128, 6808.

69. Li, Z.; Ma, J.; Lee, N. S.; Wooley, K. L.; J. Am. Chem. Soc. 2011, 133 , 1228 .

70. Hadjichristidis, N.; Iatrou, H.; Pitsikalis, M.; Pispas, S.; Avgeropoulos, A.; Prog. Polym. Sci. 2005, 30, 725.

71. Hadjichristidis, N.; Pitsikalis, M.; Pispas, S.; Iatrou, H.; Chem. Rev. 2001, 101, 3747.

72. Méry, D.; Astruc, D.; J. Mol. Catal. A: Chem. 2005, 227, 1.

73. Yun, J.; Faust, R.; Macromolecules 2002, 35, 7860.

74. Gozgen, A.; Dag, A.; Durmaz, H.; Sirkecioglu, O.; Hizal, G.; Tunca, U.; J. Polym. Sci. Part A: Polym. Chem. 2009, 47, 497.

75. Liu, J.; Li, J.; Xie, M.; Ding, L.; Yang, D.; Zhang, L.; Polymer 2009, 50, 5228

76. Lutz, J.-F.; Börner, H. G.; Prog. Polym. Sci. 2008, 33, 1.

77. Binder, J. B.; Raines, R. T.; Curr. Opin. Struct. Biol. 2008, 12, 767.

78. Al-Badri, Z. M.; Som, A.; Lyon, S.; Nelson, C. F.; Nusslein, K.; Tew, G. N.; Biomacromolecules 2008, 9, 2805.

79. Gabriel, G. J.; Madkour, A. E.; Dabkowski, J. M.; Nelson, C. F.; NuIsslein, K.; Tew, G. N.; Biomacromolecules 2008, 9, 2980.

80. Ishitsuka, Y.; Arnt, L.; Majewwski, J.; Frey, S.; Ratajczek, M.; Kjaer, K.; Tew, G. N.; Lee, K. Y. C.; J. Am. Chem. Soc. 2006, 128, 13123.

81. Maynard, H. D.; Okada, S. Y.; Grubbs, R. H.; Macromolecules 2000, 33, 6239. 
82. Maynard, H. D.; Okada, S. Y.; Grubbs, R. H.; J. Am. Chem. Soc. 2001, $123,1275$.

83. Hughes, V.; Nat. Med. 2007, 13, 1008.

84. Breitenkamp, R. B.; Emrick, T.; Biomacromolecules 2008, 9, 2495.

85. Bertin, P. A.; Gibbs, J. M.; Shen, C. K. F.; Thaxton, C. S.; Russin, W. A.; Mirkin, C. A.; Nguyen, S. T.; J. Am. Chem. Soc. 2006, 128, 4168.

86. Kolonko, E. M.; Pontrello, J. K.; Mangold, S. L.; Kiessling, L. L.; J. Am. Chem. Soc. 2009, 131, 7327.

87. Matson, J. B.; Grubbs, R. H.; J. Am. Chem. Soc. 2008, 130, 6731.

88. Smith, D.; Pentzer, E. B.; Nguyen, S. T.; Polym. Rev. 2007, 47, 419.

89. Miki, K.; Kuramochi, Y.; Oride, K.; Inoue, S.; Harada, H.; Hiraoka, M.; Ohe, K.; Bioconjugate Chem. 2009, 20, 511.

90. Miki, K.; Oride, K.; Inoue, S.; Kuramochi, Y.; Nayak, R. R.; Matsuoka, H.; Harada, H.; Hiraoka, M.; Ohe, K.; Biomaterials 2010, 31, 934.

91. Sankaran, N. B.; Rys, A. Z.; Nassif, R.; Nayak, M. K.; Metera, K.; Chen, B.; Bazzi, H. S.; Sleiman, H. F.; Macromolecules 2010, 43, 5530.

92. Gössl, I.; Shu, L.; Schluter, A. D.; Rabe, J. P.; J. Am. Chem. Soc. 2002, 124,6860

93. Zhu, B.; Han, Y.; Sun, M.; Bo, Z.; Macromolecules 2007, 40, 4494.

94. Boas, U.; Heegaard, P. M. H.; Chem. Soc. Rev. 2004, 33, 43.

95. van Heerbeek, R.; Kamer, P. C. J.; van Leeuwen, P. W. N. M.; Reek, J. N. H.; Chem. Rev. 2002, 102, 3717.

96. Liu, Z.; Zhu, L.; Shen, Z.; Zhou, W.; Cheng, S. Z. D.; Percec, V.; Ungar, G.; Macromolecules 2002, 35, 9426.

97. Ball, Z. T.; Sivula, K.; Frechet, J. M. J.; Macromolecules 2006, 39, 70.

98. Nyström, A.; Malkoch, M.; Furó, I.; Nyström, D.; Unal, K.; Antoni, P.; Vamvounis, G.; Hawker, C, Wooley, K.; Malmstro, E.; Hult, A.; Macromolecules 2006, 39, 7241.

99. Rajaram, S.; Choi, T.-L.; Rolandi, M.; Fréchet, J. M. J.; J. Am. Chem. Soc. 2007, 129, 9619.

100. Fiset, E.; Morin, J. F.; Polymer 2009, 50, 1369.

101. Beija, M.; Charreyre, M.; Martinho, J. M. G.; Prog. Polym. Sci. 2011, $36,568$.

102. Noormofidi, N.; Slugove, C.; Eur. Polym. J. 2010, 46, 694.

103. Sandholzer, M.; Slugovc, C.; Macromol. Chem. Phys. 2009, $210,651$.

104. Niedermair, F.; Sandholzer, M.; Kremser, G.; Slugovc, C.; Organometallics 2009, 28, 2888.

105. Sandholzer, M.; Lex, A.; Trimmel, G.; Saf, R.; Stelzer, F.; Slugovc, C.; J. Polym. Sci. Part A: Polym. Chem. 2007, 45, 1336.

106. Keum, S.; Ahn, S.; Roh, S.; Ma, S.; Dyes Pigm. 2010, 86, 74.

107. Myles, A. J.; Neil, R.; Branda, N. R.; Macromolecules 2003, 36, 298.

108. Wigglesworth, T. J.; Branda, N. R.; Chem. Mater. 2005, 17, 5473.

109. Liaw, D.; Huang, C.; Kang, E.; Polymer 2006, 47, 3057.

110. Odian, G.; Principles of Polymerization, $3^{\text {rd }}$ ed., Wiley: New York, 1991.

111. Sheng, X.; Kessler, M. R.; Lee, J. K.; J. Therm. Anal. Calorim. 2007, $89,459$.

112. Sheng, X.; Lee, J. K.; Kessler, M. R.; Polymer 2009, 50, 1264.

113. Bhuyan, S.; Sundararajan, S.; Sheng, X.; Kessler, M. R.; Wear 2011, $270,550$.

114. Carvalho Jr, V. P.; Ferraz, C. P.; Lima-Neto, B. S.; Eur. Polym. J. 2011, doi:10.1016/j.eurpolymj.2011.11.011.

115. Sá, J. L. S.; Nascimento, E. S. P.; Lima-Neto, B. S.; J. Appl. Polym. Sci. 2012, no prelo.

116. Hine, P. J.; Leejarkpai, T.; Khosravi, E.; Duckett, R. A.; Feast, W. J.; Polymer 2001, 42, 9413.

117. Khosravi, E.; Iqbal, F.; Musa, O. M.; Polymer 2011, 52, 243.
118. Enholm, E.; Joshi, A.; Wright, D. L.; Bioorg. Med. Chem. Lett. 2005, $15,5262$.

119. Xia, Y.; Verduzco, R.; Grubbs, R. H.; Kornfield, J. A.; J. Am. Chem. Soc. 2008, 130, 1735.

120. Merrett, K.; Liu, W.; Mitra, D.; Camm, K. D.; McLaughlin, C. R.; Liu, Y.; Watsky, M. A.; Li, F.; Griffith, M.; Fogg, D. E.; Biomaterials 2009, 30, 5403.

121. Pollino, J. M.; Nair, K. P.; Stubbs, L. P.; Adams, J.; Weck, M.; Tetrahedron 2004, 60, 7205.

122. Varghese, S.; Lele, A.; Mashelkar, R.; J. Polym. Sci. Part A: Polym. Chem. 2006, 44, 666.

123. White, S. R.; Sottos, N. R.; Geubelle, P. H.; Moore, J. S.; Kessler, M. R.; Sriram, S. R.; Brown, E. N.; Viswanathan, S.; Nature 2001, 409, 794.

124. Brown, E. N.; Kessler, M. R.; Sottos, N. R.; White, S. R.; J. Microencapsulation 2003, 20, 719.

125. Jones, A. S.; Rule, J. D.; Moore, J. S.; White, S. R.; Sottos, N. R.; Chem. Mater. 2006, 18, 1312.

126. Rule, J. D.; Brown, E. N.; Sottos, N. R.; White, S. R.; Moore, J. S.; Adv. Mater. 2005, 17, 205.

127. Brown, E. N.; White, S. R.; Sottos, N. R.; Compos. Sci. Technol. 2005, 65,2466

128. Sanada, K.; Yasuda, I.; Shindo, Y.; Plast. Rubber Compos. 2006, 35, 67.

129. Mauldin, T. C.; Rule, J. D.; Sottos, N. R.; White, S. R.; Moore, J. S.; J. R. Soc. Interface 2007, 4, 389.

130. Wilson, G. O.; Porter, K. A.; Weissman, H.; White, S. R.; Sottos, N. R.; Moore, J. S.; Adv. Synth. Catal. 2009, 351, 1817.

131. Rule, J. D.; Sottos, N. R.; White, S. R.; Polymer 2007, 48, 3520.

132. Kamphaus, J. M.; Rule, J. D.; Moore, J. S.; Sottos, N. R.; White, S. R.; J. R. Soc. Interface 2008, 5, 95.

133. Espinosa, L. M.; Meier, M. A. R.; Eur. Polym. J. 2011, 47, 837.

134. Murlu, H.; Meier, M. A. R.; J. Polym. Sci. Part A: Polym. Chem. 2010, $48,5899$.

135. Meier, M. A. R.; Macromol. Chem. Phys. 2009, 210, 1073.

136. Jeong, W.; Mauldin, T. C.; Larock, R. C.; Kessler, M. R.; Macromol. Mater. Eng. 2009, 294, 756.

137. Xia, Y.; Larock, R. C.; Polymer 2010, 51, 2508.

138. Mol, J. C.; Top. Catal. 2004, 27, 1.

139. Metzger, J. O.; Eur. J. Lipid. Sci. Technol. 2009, 111, 865.

140. Haman, K.; Badrinarayanan, P.; Kessler, M. R.; Polym. Int. 2009, 58, 738.

141. Xia, Y.; Lu, Y.; Larock, R. C.; Polymer 2010, 51, 53.

142. Tian, Q.; Larock, R. C.; J. Am. Oil Chem. Soc. 2002, 79, 479.

143. Baughman, T. W.; Wagener, K. B.; Adv. Polym. Sci. 2005, 176, 1.

144. Bermeshev, M. V.; Syromolotov, A. V.; Gringolts, M. L.; Starannikova, L. E.; Yampolskii, Y. P.; Finkelshtein, E. S.; Macromolecules 2011, 44, 6637.

145. Lian, W.-R.; Wu, H.-Y.; Wang, K.-L.; Liaw, D.-J.; Lee, K.-R.; Lai, J.-Y; J. Polym. Sci., Part A: Polym. Chem. 2011, 49, 3673.

146. Liu, J.; Liao, Y.; He, X.; Yu, J.; Ding, L.; Xie, M.; Macromol. Chem. Phys. 2011, 212, 55.

147. Lubbad, S. H.; Buchmeiser, M. R.; J. Chromatogr., A 2011, 1218, 2362.

148. Sá, J. L. S.; Vieira, L. H.; Nascimento, E. S. P.; Lima-Neto, B. S.; Appl. Catal., A 2010, 374, 194.

149. Carvalho Jr, V. P.; Ferraz, C. P.; Lima-Neto, B. S.; J. Mol. Catal. A: Chem. 2010, 333, 46. 